\title{
Issues in the management of simple and complex meconium ileus
}

\author{
A. Karimi $\cdot$ R. R. Gorter $\cdot$ Chr. Sleeboom $\cdot$ \\ C. M. F. Kneepkens $\cdot$ H. A. Heij
}

Accepted: 4 April 2011/Published online: 22 April 2011

(C) The Author(s) 2011. This article is published with open access at Springerlink.com

\begin{abstract}
Introduction Various surgical methods are used to treat meconium ileus (MI), including resection with enterostomy (RES), primary anastomosis (RPA), and purse-string enterotomy with intra-operative lavage (PSI). The aim of this study is to discuss the surgical treatment of MI, based on our experience.

Patients and methods Of the $41 \mathrm{MI}$ patients treated at our institution between 1984 and 2007, 18 had simple MI and 23 had complex MI. These groups were analyzed according to treatment modality, concentrating on length of hospital stay, complications [peritonitis, septicemia, adhesive small bowel obstruction (ASBO), and malabsorption/diarrhea], need for additional surgical procedures, mortality.

Results Of the 18 patients with simple MI, 7 (39\%) were successfully treated with diluted Gastrografin ${ }^{\circledR}$ enema. The remaining 11 patients were treated surgically: two underwent RPA, of whom one died; five had RES, of whom one developed ASBO; four underwent PSI, of whom two developed peritonitis. In the complex MI group, 14 patients underwent RPA, with peritonitis occurring in three (one died); nine underwent RES, of whom two developed ASBO.

Conclusion In patients with simple MI, conservative treatment with diluted Gastrografin ${ }^{\circledR}$ enema is an effective initial treatment in our hands. In case of failure, RES is
\end{abstract}

A. Karimi - R. R. Gorter · Chr. Sleeboom · H. A. Heij ( $\square)$ Pediatric Surgical Center of Amsterdam, Emma Children's Hospital AMC and VU University Medical Center, P. O. Box 22660, 1100 DD Amsterdam, The Netherlands e-mail: kinderchir@vumc.nl

C. M. F. Kneepkens

Department of Pediatric Gastroenterology, VU University Medical Center, Amsterdam, The Netherlands advisable. Patients with complex MI are candidates for RES. RPA and PSI seem to have higher complication rates.

Keywords Meconium ileus - Meconium peritonitis . Intestinal atresia - Cystic fibrosis - Diatrizoate . Gastrografin $^{\circledR}$

$\begin{array}{ll}\text { List of abbreviations } \\ \text { MI } & \text { Meconium ileus } \\ \text { ASBO } & \text { Adhesive secondary bowel obstruction } \\ \text { RPA } & \text { Resection with primary anastomosis } \\ \text { RES } & \text { Resection with enterostomy } \\ \text { CF } & \text { Cystic fibrosis } \\ \text { MP } & \text { Meconium peritonitis } \\ \text { PSI } & \text { Purse-string ileotomy }\end{array}$

\section{Introduction}

Meconium ileus (MI) is defined as an obstruction caused by inspissated meconium at the level of the terminal ileum $[1,2]$. In the past, MI was considered to be closely associated with cystic fibrosis (CF).However, recent studies demonstrate that MI occurs frequently in the absence of $\mathrm{CF}$ as well $[3,4]$. Though the exact pathogenesis of MI in the absence of CF is not known, a spectrum of genetic and pathological abnormalities seem to play a role [3, 4]. Two forms of MI can be discriminated: simple and complex MI $[1,2]$. In complex MI, the condition is complicated by associated gastrointestinal pathologies, such as bowel atresia, necrosis, and perforation. When perforation occurs antenatally, meconium can spill into the abdominal cavity, causing (sterile) meconium peritonitis (MP), which may 
present after birth, with calcifications visible on plain abdominal X-ray [1, 5-7]. In general, the main presenting symptom of MI in newborns is the failure to pass meconium after birth. Complex MI represents a surgical emergency. Differentiating simple and complex MI could be difficult, in spite of the demonstration of marked air-fluid levels and intra-abdominal calcifications on abdominal X-ray, which may be helpful [1, 7-9].

Several options are available for the treatment of MI, but there is a relative lack of literature in examining the treatment outcomes and guidelines are lacking. A vast majority of authors consider enema reductions, such as saline, $\mathrm{N}$-acetyl cysteine and Gastrografin ${ }^{\circledR}$, as the initial treatment of choice for simple MI [10-13]. The use of enemas is, however, not without risk and the reported success rates vary [11-15]. In case of failure, complication, or complex MI, a surgical procedure is required. Enterotomy and bowel irrigation; T-tube ileostomy; resection of atretic segments, compromised bowel, or strongly dilated bowel followed by primary anastomosis (RPA); Bishop-Koop ileostomy; Santulli procedure and Mikulicz procedure are common procedures for MI [1, 5-7, 16-26]. Although every author seems to have a preferred technique, only few comparative studies have been performed [16-26].

The aim of this retrospective case series study is to compare and discuss various treatment options for neonates with both simple and complex MI.

\section{Patients and methods}

A total of 44 neonates, treated at the Pediatric Surgical Center Amsterdam between January 1984 and December 2007, met the diagnostic criteria for either simple or complex MI. Newborns with meconium obstruction in other parts of the intestine, neonates with meconium plug syndrome, and newborns with other mechanical or functional causes of bowel obstruction were excluded. Three patients were excluded because of incomplete data concerning the surgical procedure. The remaining 41 neonates were divided into two groups, depending on the type of MI: 18 with simple MI and 23 with complex MI.

Both the groups were subdivided based on the initial treatment. All simple MI patients were initially treated with contrast enema under fluoroscopy. In our center, diluted Gastrografin ${ }^{\circledR}$ is used in the ratio 1 part Gastrografin ${ }^{\circledR}$ $\left(100+660 \mathrm{mg} / \mathrm{ml}\right.$, somol $\left.=2,015 \mathrm{mmol} / \mathrm{kgH}_{2} \mathrm{O}\right)$ in 1 part $0.9 \%$ sodiumchloride (hyperosmolar) in case of meconium ileus. All patients underwent one attempt. During the administration general precautions were taken. In case of failure or complication, one of the following surgical procedures was used: resection with primary anastomosis (RPA), resection with temporary double-barreled enterostomy (RES), or purse-string ileotomy with irrigation (PSI). All newborns with complex MI underwent surgery, either RPA or RES. The procedures were performed by one of the 15 pediatric surgeons, supervised by a senior consultant. The choice of the procedure depended partly on perioperative findings, such as bowel viability, and partly upon the preference of the operating surgeon. Protocols concerning the technical procedure as well as perioperative care were used in order to standardize all treatments.

From the patients record data were extracted for gestational age (in weeks), birth weight (in grams), sex, comorbidity, type of MI, length of hospital stay, time to complete enteral feeding, length of bowel resection, mortality rate, need for additional surgery, and complications. All children were tested for cystic fibrosis (CF) by means of sweat tests after the first week of life (sodium chloride concentrations $>60 \mathrm{mmol} / \mathrm{L}$ being indicative of $\mathrm{CF}$ ) and/or DNA analysis of the CFTR gene. Mutations tested included $\Delta$ F508, F508C, G542X, R553X, N1303K, R1162X, and E60X. Complications were registered after the initial surgical procedure and divided into four main categories:

1. complications related to the surgical procedure, e.g., peritonitis due to leakage of anastomosis, stoma prolapse;

2. general surgical complications, e.g., adhesive small bowel obstruction (ASBO);

3. illness related complications, e.g., high-output diarrhea;

4. general (non-surgical) complications, e.g., septicemia, urinary tract infection, pneumonia.

Septicemia was defined as either a positive blood culture or a cluster of clinical signs, including tachycardia $(>160$ beats/min), tachypnea $(>50$ breathes $/ \mathrm{min})$, pyrexia $\left(>38^{\circ} \mathrm{C}\right)$, shivering and hypotension $(<54 / 28 \mathrm{mmHg})$. High-output diarrhea was defined as diarrhea accompanied by malabsorption and failure to thrive. ASBO was defined as small bowel obstruction caused by intra-abdominal adhesions as a result of laparotomy, requiring reoperation. Complications were registered up to 1 year after surgery.

We registered the length of performed resections, and the time to complete enteral feeding. Unfortunately no accurate data could be retrieved concerning growth.

After discharge, patients with $\mathrm{CF}$ were monitored by either the Emma Children's Hospital or the VU University Medical Center cystic fibrosis team. Children without CF were discharged from the 3-monthly follow-up after 1 year. Because of the small number of cases, statistical analysis was limited to comparison of complication rates.

\section{Results}

The baseline characteristics of the simple and complex MI group are shown in Tables 1 and 2. 
Table 1 Characteristics of the simple MI group $(n=18)$

\begin{tabular}{llllll}
\hline & & $\begin{array}{l}\text { Diatrizoate enema } \\
(n=7)\end{array}$ & $\begin{array}{l}\text { Resection with primary } \\
\text { anastomosis }(n=2)\end{array}$ & $\begin{array}{l}\text { Resection with temporary } \\
\text { enterostomy }(n=5)\end{array}$ & $\begin{array}{l}\text { Purse-string } \\
\text { ileotomy }(n=4)\end{array}$ \\
\hline Male/female ratio & & $4 / 3$ & $0 / 2$ & $2 / 3$ & $2 / 2$ \\
Gestational age (weeks) & Mean \pm SD & $37 \pm 2$ & $38 \pm 0$ & $39 \pm 3$ & $39 \pm 3$ \\
Birth weight (g) & Mean \pm SD & $2,278 \pm 636$ & $2,938 \pm 265$ & $3,117 \pm 829$ & $3,195 \pm 889$ \\
Cystic fibrosis & Yes/no & $3 / 4$ & $2 / 0$ & $5 / 0$ & $4 / 0$ \\
\hline
\end{tabular}

Table 2 Characteristics of the complex MI group $(n=23)$

\begin{tabular}{llll}
\hline & & $\begin{array}{l}\text { Resection } \\
\text { with primary } \\
\text { anastomsis } \\
(n=14)\end{array}$ & $\begin{array}{l}\text { Resection } \\
\text { with temporary } \\
\text { enterostomy } \\
(n=9)\end{array}$ \\
\hline $\begin{array}{l}\text { Male/female ratio } \\
\text { Gestational age (weeks) }\end{array}$ & Mean $\pm \mathrm{SD}$ & $8 / 6$ & $8 / 1$ \\
$\begin{array}{l}\text { Birth weight (g) } \\
\text { Cystic fibrosis }\end{array}$ & $\begin{array}{l}\text { Mean } \pm \mathrm{SD} \\
\text { Yes/no }\end{array}$ & $2,760 \pm 840$ & $37 \pm 3$ \\
\hline
\end{tabular}

\section{Simple meconium ileus}

\section{Conservative treatment}

All patients of the simple MI group $(n=18)$ were initially given a contrast enema under fluoroscopy. All four patients without $\mathrm{CF}$ and 3/14 CF patients (21\%) were successfully treated with 1:1 diluted Gastrografin ${ }^{\circledR}$ enemas. In 10 patients, Gastrografin ${ }^{\circledR}$ enemas were unsuccessful, as was iohexol in another patient. None of the patients suffered from complications after the enema administration.

\section{Surgical treatment}

The 11 patients (all with $\mathrm{CF}$ ) in whom contrast enema had failed underwent surgical intervention Table 3. RPA was performed in two patients, both had several complications as outlined in Table 3. Both required additional surgery because of ASBO: enterostomy in one patient and adhesiolysis in the other. The former suffered from 14 episodes of septicemia and died after 380 days of admission. RES was performed in five patients, one of them requiring RPA because of ASBO. Four patients were treated with PSI and irrigation with 1:1 Gastrografin $^{\circledR}$ enema, two of whom required enterostomy and additional adhesiolysis because of peritonitis following perforation. No differences existed between the treatment groups with regard to complications, time to complete enteral feeding, length of resection, initial hospital stay, or mortality rate.
Complex meconium ileus

Fifteen patients of the complex MI group, all without signs of perforation or calcifications, were initially given 1:1 Gastrografin ${ }^{\circledR}$ enemas for diagnostic purposes. In one patient extravasation of the enema fluid was seen as an indication of perforation. All 23 patients underwent surgery; complications after surgery are outlined in Table 4. RPA was performed in 14 patients, three of whom required additional surgery: suture of perforation and enterostomy in two patients and adhesiolysis because of ASBO in one. Additionally, one patient suffered from a total of 11 episodes of septicemia and died after 431 days of admission. RES was performed in nine patients, two of whom required additional surgery: adhesiolysis for ASBO in one and exploratory laparatomy persisting signs of intestinal obstruction in the other. All patients of this group survived.

\section{Discussion}

Simple meconium ileus

Patients with simple MI were initially treated with contrast enema. In our study, 1:1 diluted Gastrografin ${ }^{\circledR}$ was safe and effective in resolving the obstruction in 39\% of the patients with simple MI, which is in line with the published success rates ranging $5-83 \%$ [10-17]. The fact that all four patients without $\mathrm{CF}$ in this group were successfully treated may well reflect the fact that meconium in these patients is less 
Table 3 Complications in surgically treated simple MI patients $(n=11)$

\begin{tabular}{|c|c|c|c|c|}
\hline Category & Complication & $\begin{array}{l}\text { Resection } \\
\text { with primary } \\
\text { anastomosis }(n=2)\end{array}$ & $\begin{array}{l}\text { Resection } \\
\text { with enterostomy } \\
(n=5)\end{array}$ & $\begin{array}{l}\text { Purse-string } \\
\text { ileotomy } \\
(n=4)\end{array}$ \\
\hline Specific surgical complications & $\begin{array}{l}\text { Peritonitis due } \\
\text { to leakage } \\
\text { of anastomosis }\end{array}$ & 1 & 0 & 2 \\
\hline \multirow[t]{2}{*}{ General surgical complications } & ASBO & 2 & 1 & 0 \\
\hline & Wound infection & 0 & 0 & 0 \\
\hline Resection length $(\mathrm{cm})($ mean \pm SD) & & $15.0 \pm 7.07$ & $3.33 \pm 5.77$ & $0.00 \pm 0.00$ \\
\hline $\begin{array}{l}\text { Time to complete enteral feeding (days) } \\
\text { (mean } \pm \text { SD) }\end{array}$ & & $10 \pm 0$ & $32.8 \pm 37.6$ & $21.7 \pm 9.87$ \\
\hline Illness related complications & Malabsorption diarrhea & 0 & 0 & 1 \\
\hline \multirow[t]{2}{*}{ General (non-surgical) complications } & Pneumonia & 0 & 0 & 0 \\
\hline & Septicemia & 2 & 5 & 1 \\
\hline Hospital stay (mean \pm SD) & & $202 \pm 252$ & $23 \pm 6$ & $38 \pm 23$ \\
\hline Additional surgery needed & & 2 & 1 & 2 \\
\hline Mortality rate & & 1 & 0 & 0 \\
\hline
\end{tabular}

Table 4 Complications in the complex MI group $(n=23)$

\begin{tabular}{llll}
\hline Category & Complications & $\begin{array}{l}\text { Resection with primary } \\
\text { anastomosis }(n=14)\end{array}$ & $\begin{array}{l}\text { Resection with } \\
\text { enterostomy }(n=9)\end{array}$ \\
\hline Specific surgical complications & $\begin{array}{l}\text { Peritonitis due to leakage } \\
\text { of anastomosis }\end{array}$ & $2(14 \%)$ & 0 \\
General surgical complications & ASBO & & 0 \\
& Wound infection & $1(7 \%)$ & $2(22 \%)$ \\
Length of resection $(\mathrm{cm})$ (mean \pm SD) & & 0 & $20.8 \pm 20.6$ \\
Time to complete enteral feeding $\quad$ & $18.7 \pm 9.40$ & $37.8 \pm 43.7$ \\
$\quad$ days) (mean \pm SD) & Malabsorption diarrhea & $19.5 \pm 8.45$ & $3(33 \%)$ \\
Illness related complications & Pneumonia & 0 & 0 \\
General (non-surgical) complications & Septicemia & 0 & $1(11 \%)$ \\
& Urinary tract infection & $1(7 \%)$ & $2(22 \%)$ \\
Hospital stay (mean \pm SD) & & 0 & $60 \pm 39$ \\
Additional surgery needed & & $57 \pm 108$ & $2(22 \%)$ \\
Mortality rate & & $3(21 \%)$ & 0
\end{tabular}

viscous. Though a recent report suggests that repeated enemas might increase the success rate of the conservative treatment [18], we chose to reduce the risk of complications by not repeating an unsuccessful attempt.

In mice, Gastrografin ${ }^{\circledR}$ was shown to be more efficacious for the relief of constipation than agents such as saline, Tween-80, Dnase and $N$-acetyl cysteine [11]. Apart from saline, all agents reduced the viscosity of human meconium immediately after administration; of these, $N$-acetylcysteine reduced viscosity with more than $99 \%$, but only after an incubation period of $6 \mathrm{~h}$. The use of hyperosmolar agents such as Gastrografin ${ }^{\circledR}$ is, however, not without risk. Perforation, hypovolemia, electrolyte loss, and hepatotoxicity have been reported [14, 18-20] the risk of complications can be diminished by taking care of precautions such as diluting the solution with equal amounts of water, limitation of administration pressure, and the provision of intravenous access to maintain optimal fluid administration. Furthermore, contraindications including signs indicative of perforation should be identified with the help of X-ray studies. None of our simple MI patients suffered from complications, whereas in one complex MI patient leakage of contrast into the abdominal cavity occurred, apparently due to the pre-existing perforation sealed by the intestinal loops. Overall, the minimal invasive nature, the relatively high success rates and the 
low complication rates make Gastrografin ${ }^{\circledR}$ enema the first choice in simple MI.

In case of failed contrast enema or complications in simple MI, resection with temporary double-barreled enterostomy seems to be the preferable approach. Severe complications related to the surgical procedure itself, such as peritonitis due to anastomotic leakage and perforation due to frequent manipulation, were more often seen in RPA and PSI. Decreased viability of severely dilated bowel in combination with the previous injection of hypertonic solution and manipulation during surgery aimed at advancing the meconium might underlie the greater complication rate following surgery without enterostomy. Moreover, the enterostomy in RES has the advantage that enemas can be applied after surgery in order to evacuate any remaining meconium, so that manual manipulation during surgery can be kept at minimum. The disadvantages of enterostomy, such as enterostomy care, the need for an extra surgical procedure, prolonged hospital stay, and the risk of high-output diarrhea do not outweigh the obvious reduced risk of anastomotic leakage and perforation.

Recent literature does not provide clear guidelines concerning the surgical treatment of simple MI. The Bishop-Koop enterostomy, introduced in 1957 consisting of an end-to-side anastomosis combined with a chimneylike enterostomy, has been widely used [13, 21, 22]. It has the advantage of easy extraperitoneal, bed-side closure of the enterostomy. However, anastomosis is made, in the intraperitoneal cavity, leading to a higher risk of anastomotic leakage. For this reason, we prefer the doublebarreled enterostomy. Although PSI is reported to result in reduced admission duration and a relatively low complication rate $[13,16,20]$, our data suggest that PSI is not without risk. The injection of hypertonic solution combined with squeezing and milking of the neonatal gut increases the risk of perforation, as is the case with suturing the ileotomy in tissue with impaired vascularisation. RPA, finally, has fallen out of grace for simple MI [23], as the primary anastomosis of compromised intestine might be hazardous. Recent techniques include variants of enterotomy with irrigation and T-tube ileostomy [24, 25], but information on these techniques is limited.

\section{Complex MI}

In the complex MI group, surgical intervention is mandatory. In this group as well, resection with enterostomy in our hands was the safest treatment. None of the patients developed peritonitis, as compared to $21 \%$ of the RPA group. The reoperation rates, apart from closure of enterostomy, in RES and RPA were similar. Although RES creates the need of additional surgery to close the enterostomy, this is a safe, elective procedure. Complication rates between patients with and without $\mathrm{CF}$ were similar.

Conclusive evidence for the superiority of one or another procedure in complex MI has not been published. RPA has been used infrequently, mostly with atresia. Rescorla and Grosfeld [13] did not mention the complications while reporting on RPA in 13 out of 27 complex MI patients with atresia, volvulus or perforation. Escobar et al. [18] suggest that RPA should only be used in case of atresia, RES being preferable in complex MI patients. However, most studies report no significant differences between RPA and RES apart from duration of hospital stay, or focus only on one surgical procedure [13, 24, 25]. Jawaheer et al. [26] report complications requiring additional surgery in 4 out of 13 patients (31\%) after RPA, which is in line with our experience (complications in $21 \%$ ). They consider RPA as a safe option for all complex MI patients apart from those with unstable condition and impaired perfusion of intestinal margins, the advantages being reduced hospital stay, avoidance of stoma-related morbidity and second laparotomy for stoma closure [26]. However, impaired intestinal perfusion, is often present in complex MI patients, while the manipulation of neonatal intestine for the evacuation of viscous meconium might further impair blood supply and intestinal integrity. As it is hard to objectively assess the viability and condition of the intestine, we consider intra-abdominal anastomosis in these circumstances as hazardous. Fashioning of a doublebarreled enterostomy requires less manipulation of the neonatal intestine and enables the application of enemas after surgery, while elective enterostomy closure is a safe procedure.

\section{Conclusion}

As this is a retrospective study with a limited number of patients, collected over a period of 23 years, the results should be interpreted with care. Yet, our results suggest that RPA should be used with caution, both in patients with simple and with complex MI. RES seems to be the safer procedure, which might be explained by the fact that intestinal viability is hard to determine during surgery. Enterostomy prevents peritonitis due to anastomotic leakage and enables postoperative retrograde enema use, the necessity of a second operation for the restoration of intestinal continuity being a relative disadvantage. As the present evidence precludes the composition of solid guidelines, prospective multicenter studies seem to be warranted.

This study has been approved by the ethics board of the VU University medical center. 
Open Access This article is distributed under the terms of the Creative Commons Attribution Noncommercial License which permits any noncommercial use, distribution, and reproduction in any medium, provided the original author(s) and source are credited.

\section{References}

1. Wyllie R (2007) Intestinal atresia, stenosis and malrotation. In: Kliegmann RM, Behrman RE, Jenson HB, Stanton BF et al (eds) Nelson textbook of pediatrics, 18th edn. Saunders Elsevier, Philadelphia, pp 1559-1562

2. Ziegler MM (1994) Meconium ileus. Curr Probl Surg 31:731-777

3. Gorter RR, Karimi A, Sleeboom Chr et al (2010) Clinical and genetic characteristics of meconium ileus in newborns with and without cystic fibrosis. J Pediatr Gastroenterol 50(5):569-572

4. Fakhoury K, Durie PR, Levinson H et al (1992) Meconium ileus in the absence of cystic fibrosis. Arch Dis Child 67:1204-1206

5. Ein SH (1994) Meconium ileus. In: Freeman NV, Burge DM, Griffiths DM et al (eds) Surgery of the newborn. Churchill Livingstone, London, pp 139-157

6. Rescorla FJ (1998) Meconium Ileus. In: O’Neill jr JA, Rowe MI, Grosfeld JL et al (eds) Pediatric surgery, 5th edn. Mosby Yearbook, Missouri, pp 1159-1171

7. Kieley E (2003) Meconium ileus. In: Puri P (ed) Newborn surgery, 2nd edn. Arnold, London, pp 465-471

8. White H (1956) Meconium ileus: a new roentgen sign. Radiology $66: 567-571$

9. Neuhauser EBD (1946) Roentgen changes associated with pancreatic insufficiency in the early life. Radiology 46:319-328

10. Noblett HR (1969) Treatment of uncomplicated meconium ileus by Gastrografin ${ }^{\circledR}$ enema: a preliminary report. J Pediatr Surg 4:190-197

11. Burke MS, Ragi JM, Karamanoukian HL et al (2002) New strategies in non-operative management of meconium ileus. J Pediatr Surg 5:760-764

12. Boyd A, Carachi R, Azmy AF et al (1988) Gastrografin ${ }^{\circledR}$ enema in meconium ileus: the persistent approach. Pediatr Surg Int 3:139-140
13. Rescorla FJ, Grosfeld JL (1993) Contemporary management of meconium ileus. World J Surg 17:318-325

14. Ein SH, Shandling B, Reily BJ et al (1987) Bowel perforation with non operative treatment of meconium ileus. J Pediatr Surg 2:146-147

15. Copeland DR, St Peter SD, Sharp SW et al (2009) Diminishing role of contrast enema in simple meconium ileus. J Pediatr Surg 44:2130-2132

16. Nguyen LT, Youssef S, Guttman FM et al (1986) Meconium ileus: is a stoma necessary? J Pediatr Surg 21:766-768

17. D'Agostino S, Musi L, Fabbro MA et al (1995) Uncomplicated meconium ileus: efficacy of enterotomy and bowel irrigation. Pediatr Surg Int 10:329-331

18. Escobar MA, Grosfeld JL, Burdick JJ et al (2005) Surgical considerations in cystic fibrosis: a 32-year evaluation of outcomes. Surgery 138:560-572

19. Manesksha FR, Betta J, Zawin M et al (1984) Intraoperative hypoxia and hypotension caused by gastrografin-induced hypovolemia. Anesthesiology 61:454-456

20. Venugopal S, Shandling B (1979) Meconium ileus: laparotomy without resection, anastomosis, or enterostomy. J Pediatr Surg 14:715-718

21. Bishop HC, Koop CE (1957) Management of meconium ileus; resection, Roux-en-Y anastomosis and ileostomy irrigation with pancreatic enzymes. Ann Surg 145:410-414

22. Del Pin CA, Czyrko C, Ziegler MM, Scanlin TF, Bishop HC (1992) Management and survival of meconium ileus a 30 year review. Ann Surg 2:179-185

23. Nagar H (2006) Meconium ileus: Is a single procedure adequate? Asian J Surg 29:161-164

24. Mak GZ, Harberg FJ, Hiatt P et al (2000) T-tube ileostomy for meconium ileus: four decades of experiences. J Pediatr Surg 35:349-352

25. Steiner Z, Mogilner J, Siplovich L et al (1997) T-tubes in the management of meconium ileus. Pediatr Surg Int 12:140-141

26. Jawaheer J, Khalil B, Plummer T et al (2007) Primary resection and anastomosis for complicated meconium ileus: a safe procedure? Pediatr Surg Int 23:1091-1093 